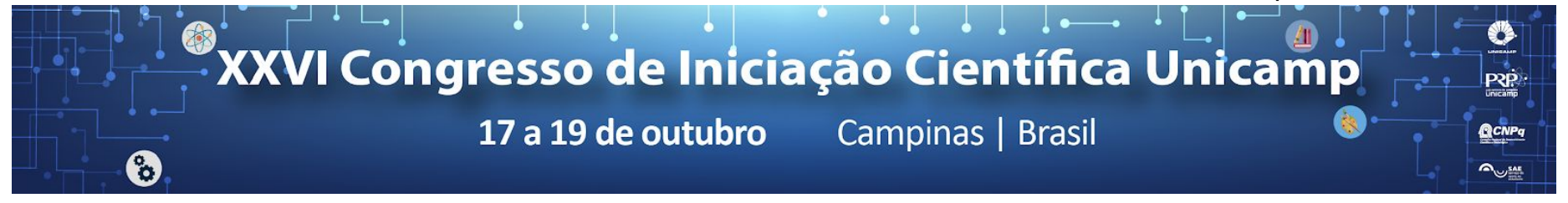

\title{
Análise da toxicidade de lodo de esgoto em sementes
}

\author{
Fernanda T. Makiyama*, Elaine C. C. Poletti, Marta S. G. Pires
}

\section{Resumo}

O aumento na geração de lodo de esgoto traz a necessidade de uma destinação final ambientalmente adequada. Rico em matéria orgânica e nutrientes importantes para as plantas, uma alternativa viável seria a disposição desse resíduo em solo agrícola. A possível presença de metais potencialmente tóxicos, patógenos e compostos orgânicos persistentes no lodo pode, contudo, trazer riscos ao meio ambiente e à saúde humana. $\mathrm{O}$ objetivo deste trabalho foi avaliar, a partir de testes de fitotoxicidade, a toxicidade do lodo de esgoto fresco, lodo de esgoto estocado e fertilizante químico em sementes de hortaliças e comparar a sensibilidade entre as espécies vegetais utilizadas.

\section{Palavras-chave:}

Lodo de esgoto, toxicidade, sementes

\section{Introdução}

O crescimento da população e a ampliação dos serviços de coleta e tratamento de esgotos leva a um aumento na geração de lodo de esgoto (LE) pelas Estações de Tratamento de Esgoto (ETE). Esse resíduo pode trazer melhorias das propriedades químicas e físicas do solo, o que torna sua aplicação agrícola uma destinação final interessante, além de viável e de baixo custo. Porém, o LE pode ainda conter compostos nocivos a depender de sua origem. $O$ presente estudo visa avaliar a toxicidade de uma amostra de LE proveniente da Região Metropolitana de Campinas, comparando diferentes tratamentos e sementes.

\section{Resultados e Discussão}

O teste de fitotoxicidade seguiu a norma "Ecological Effects Test Guidelines" OPPTS 850.4200 - Seed Germination/Root Elongation Toxicity Test (USEPA, 1996). Foram utilizadas sementes de nabo (Raphanus sativus var. acanthioformis), rabanete branco (Raphanus sativus) e repolho (Brassica oleracea var. capitata), e três substratos diferentes, sendo LE fresco (LEF), LE estocado (LEE) por 35 dias e fertilizante químico, além do tratamento controle. Os resultados foram analisados conforme TAM e TIQUIA (1994).

Com exceção para $1 \mathrm{~g} / \mathrm{L}$ em sementes de nabo, o LEE apresentou menor toxicidade quando comparado ao LEF nas concentrações correspondentes, como ilustra a Figura 1.

Figura 1. Alongamento relativo de raízes para LEF (a) e LEE (b)
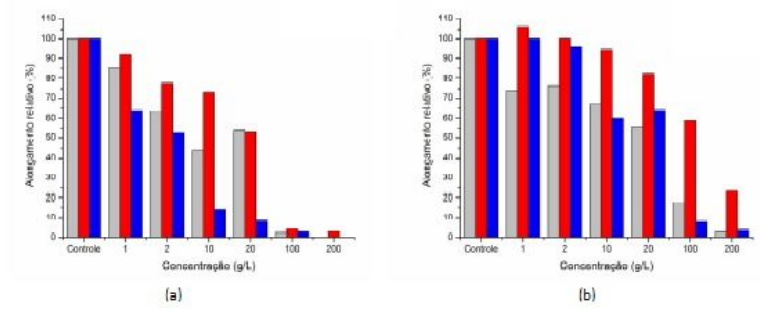

A dose de fertilizante recomendada pelo fabricante $(6 \mathrm{~g} / \mathrm{L})$, causou, nas três espécies, maior efeito inibitório no alongamento das raízes do que as doses de até $10 \mathrm{~g} / \mathrm{L}$ do LEE. Algumas placas tratadas com fertilizante apresentaram plântulas mais frágeis e escurecidas, como pode ser visto na Figura 2.

Figura 2. Plântulas de rabanete com aspecto atípico

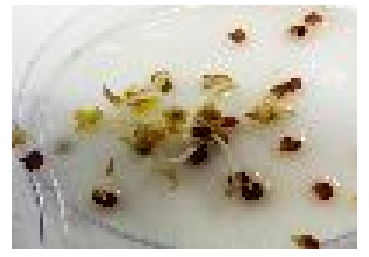

\section{Conclusões}

Concentrações de até $10 \mathrm{~g} / \mathrm{L}$ de LEE foram mais eficientes no desenvolvimento das plântulas quando comparadas ao tratamento com fertilizante químico na dose recomendada pelo fabricante.

A estabilização do lodo mostrou-se fator determinante na redução de sua fitotoxicidade. A disposição agrícola do lodo seria segura em baixas concentrações, de até $2 \mathrm{~g} / \mathrm{L}$, após o processo de estocagem.

Entre as espécies estudadas, o rabanete é a mais resistente, enquanto $\mathrm{o}$ repolho apresentou maior sensibilidade ao LEF. Nabo mostrou-se a espécie menos beneficiada pelo processo de estocagem do lodo e mais vulnerável ao fertilizante.

\section{Agradecimentos}

Ao SAE, pela bolsa, e aos mestrandos e técnicos de laboratório, pelo auxílio.

\footnotetext{
${ }^{1}$ ENVIRONMENTAL PROTECTION AGENCY (USEPA). Ecological effects test guidelines OPPTS 850.4200 seed germination/root elongation toxicity test public draft. 1996.

${ }^{2}$ Tam, N. F. Y.; Tiquia, S. M. Assessing toxicity of 'spent sawdust pig-litter' using seed germination technique. Resources, Conservation and Recycling Journal. 1994, v. 11, p. 261-274.
} 